\title{
Photodynamic therapy for malignant tumours of the ampulla of Vater
}

\author{
A M Abulafi, J T Allardice, N S Williams, N van Someren, C P Swain, C Ainley
}

\begin{abstract}
Ten patients with ampullary carcinoma, not suitable for surgery, were treated with endoscopic photodynamic therapy (PDT) to evaluate the feasibility and safety of treatment. Patients received $4 \mathrm{mg} \mathrm{kg}^{-1}$ of haematoporphyrin derivative intravenously. Two days later, a duodenoscopy was performed and red (630 $\mathrm{nm}$ ) light delivered to the tumour at fixed energy densities of $50 \mathrm{~J}$ or $200 \mathrm{~J} \mathrm{~cm}^{-1}$ per application, depending on the type of optical fibre used. The tumours were treated by three or four light applications at each session. Treatment was repeated up to five times at intervals of three to six months. The sole complication of PDT was moderate skin photosensitivity, which occurred in three patients. Tumour size was assessed at four to eight weekly intervals. In the absence of macroscopic tumour, biopsy specimens were taken. In three patients with small tumours confined to the ampulla, remission was obtained for periods ranging from eight to 12 months. In a further four patients with small tumours bulk was greatly reduced. There was little response in three patients with extensive duodenal involvement. Therefore PDT for ampullary carcinoma is both feasible and safe, and with refinement may prove curative for small tumours. (Gut 1995; 36: 853-856)
\end{abstract}

Keywords: photodynamic therapy, ampullary carcinoma.

Carcinoma of the ampulla of Vater is a rare malignancy, and with tumours arising from either the pancreatic or bile ducts beneath the ampulla and from adjacent duodenal mucosa, are often referred to collectively as periampullary carcinomas. ${ }^{1}$ Because of their position, these tumours present early with biliary obstruction, and therefore have a better prognosis than other pancreatic malignancy. ${ }^{2}$

The optimal treatment for ampullary carcinoma is pancreaticoduodenectomy. ${ }^{3-9}$ Although results continue to improve, surgery is still associated with considerable morbidity and an appreciable mortality and so is limited to patients with favourable tumours and who are medically fit. Local excision has been proposed as a less invasive and safer alternative, 1011 but there can be an unacceptable high rate of recurrence. ${ }^{9}$ Patients not suitable for pancreaticoduodenectomy are usually palliated by either endoscopic drainage ${ }^{512}$ or biliary and duodenal bypass surgery. ${ }^{4-9}$
Photodynamic therapy (PDT) is an experimental treatment, which is potentially curative for small accessible tumours. ${ }^{13}$ A photosensitising drug is given and is selectively retained in malignant compared with normal tissue. ${ }^{14}$ Activation of the drug within the tumour by visible light of an appropriate wavelength releases singlet oxygen, which causes oxidative tumour necrosis with minimal damage to surrounding normal tissue. ${ }^{15}$ Healing takes place by regeneration rather than scarring resulting in good functional results without fibrosis or stricturing. ${ }^{16}$ Ampullary carcinoma is an ideal candidate for PDT and we have therefore conducted a phase I pilot study to determine the feasibility and safety of this treatment in patients not suitable for surgery.

\section{Methods}

\section{Patients}

Ten patients, six male and four female age range 55-78 years (median 71), with histologically confirmed ampullary carcinoma were treated with PDT (Table I). Four patients were unsuitable for surgery because of age (74, 75 , and 78 years); two had chronic airflow limitation; one each had cerebrovascular disease, hepatic metastases, and a prosthetic aortic valve; and one was a Jehovah's Witness. All 10 had previous endoscopic biliary drainage by either stent (six patients) or sphincterotomy (four patients) and were not jaundiced at the time of PDT (haematoporphyrin derivative is excreted into bile and hence biliary obstruction will result in high tissue concentrations of haematoporphyrin derivative with associated toxicity and prolonged skin photosensitivity). The experimental nature of the treatment was explained to the patients and informed consent obtained. Patients were advised to avoid exposure to sun or bright light for up to eight weeks after receiving haematoporphyrin derivative to

TABLe I Patient details

\begin{tabular}{llllll}
\hline Patient & $\begin{array}{c}\text { Age } \\
(y)\end{array}$ & Sex & $\begin{array}{l}\text { Reason unfit } \\
\text { for surgery }\end{array}$ & $\begin{array}{l}\text { Biliary } \\
\text { drainage }\end{array}$ & $\begin{array}{l}\text { Type of } \\
\text { tumour }\end{array}$ \\
\hline 1 & 55 & M & Prosthetic heart valve & Stent & I \\
2 & 63 & M & CAL & ES & I \\
3 & 71 & M & CVA & Stent & I \\
4 & 74 & F & Age & Stent & I \\
5 & 59 & F & Jehovah's Witness & ES & II \\
6 & 75 & F & Age & ES & II \\
7 & 78 & F & Age & ES & II \\
8 & 71 & M & CAL & Stent & III \\
9 & 73 & M & Age & Stent & III \\
10 & 56 & M & Liver metastases & Stent & III
\end{tabular}

$\mathrm{CAL}=$ chronic airflow limitation; $\mathrm{CVA}=$ cerebrovascular disease; ES = endoscopic sphincterotomy. Tumour type: $I$ confined to the papilla: II localised extension beyond papilla $<3 \mathrm{~cm}$ in diameter; III extension $>3 \mathrm{~cm}$ in diameter. 

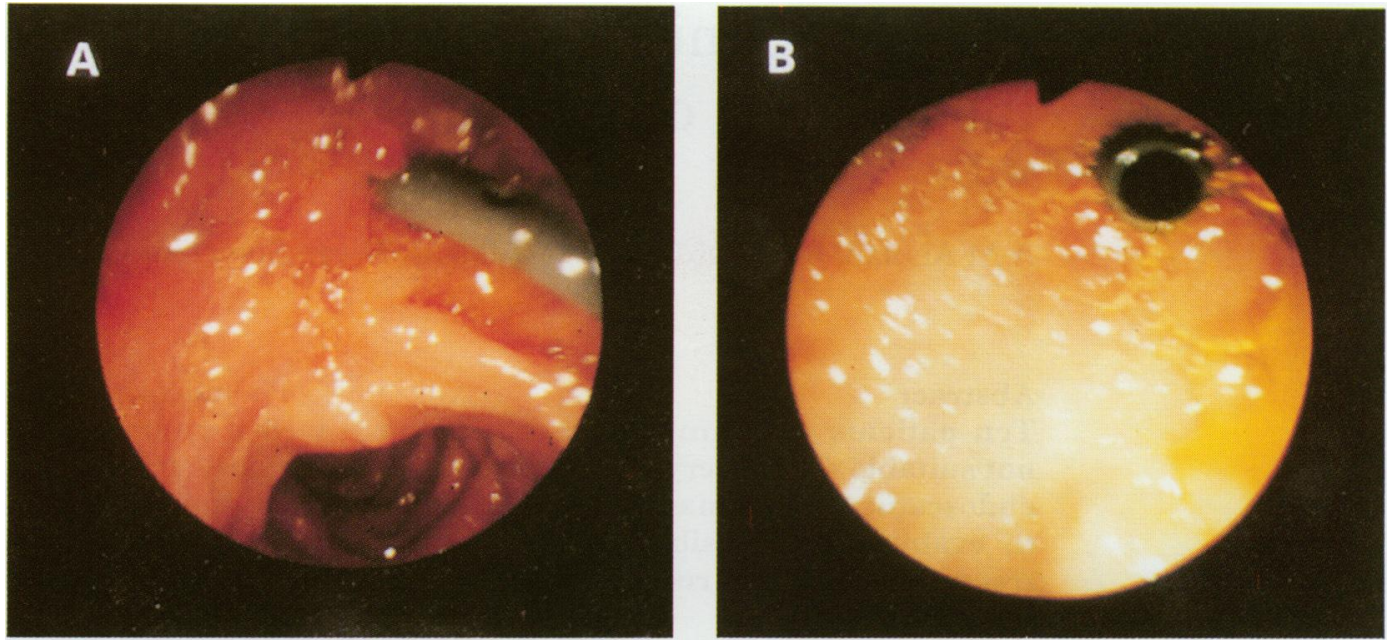

Figure 1: Patient 4-complete response. (A) Before treatment; (B) after treatment.

prevent photosensitivity. The study was approved by Tower Hamlets Health Authority ethics committee.

\section{Tumour assessment}

The site and size of the tumours were measured at duodenoscopy, and photographs taken. The patients were divided into three groups according to extent: tumour confined to the ampulla (group I); tumour with local spread $<3 \mathrm{~cm}$ in diameter (group II); tumour $>3 \mathrm{~cm}$ in diameter (group III).

\section{Photodynamic therapy}

The photosensitiser was haematoporphyrin derivative and was prepared jointly by the surgical unit and the pharmacy at The Royal London Hospital using Lipson's method ${ }^{17}$ with modifications according to Gomer ${ }^{18}$ and Kessel. ${ }^{19}$ A CU25 copper-vapour laser (Oxford Lasers, Oxford, UK) pumping a DL $10 \mathrm{~K}$ laser containing a mixture of rhodamine 640 and rhodamine 590 was used. Illumination of the target was with red light tuned at $630 \mathrm{~nm}$.

Haematoporphyrin derivative $4 \mathrm{mg} \mathrm{kg}^{-1}$ was given by slow intravenous injection. Forty eight hours later duodenoscopy was carried out using an Olympus TJF20 duodenoscope under sedation with pethidine and diazepam. Initially a flat tipped optical fibre was used and applied to the surface of the tumour, but this was changed to an optical fibre with a $1 \mathrm{~cm}$ cylindrical diffusing tip to increase the volume of malignant tissue treated for the latter part of the study. The dif-

TABLE II Treatment details and response

\begin{tabular}{rllll}
\hline Patient & $\begin{array}{l}\text { No of } \\
\text { sessions }\end{array}$ & $\begin{array}{l}\text { Laser } \\
\text { tip }\end{array}$ & $\begin{array}{l}\text { Type of } \\
\text { tumour }\end{array}$ & Response \\
\hline 1 & 5 & F and D & I & $\begin{array}{l}\text { Remission (8 months) } \\
2\end{array}$ \\
3 & F & I & Remission (6 months) \\
3 & 2 & F and D & I & Remission (8 months) \\
4 & 1 & D & I & Remission (12 months) \\
5 & 2 & F and D & II & Partial \\
6 & 2 & F and D & II & Partial \\
7 & 2 & F and D & II & Partial \\
8 & 2 & F and D & III & Minimal \\
9 & 2 & F & III & Minimal \\
10 & 1 & F & III & Partial \\
\hline
\end{tabular}

Laser tip: $\mathrm{F}$ flat tipped; $\mathrm{D}$ diffuser. fusing tip was inserted into the tumour either by direct puncture in patients treated by sphincterotomy or in patients with a stent in situ adjacent and parallel to the stent. Red light was delivered to the tumour to achieve an energy density of $50 \mathrm{~J} / \mathrm{site}$ (flat tip) or $200 \mathrm{~J} \mathrm{~cm}^{-1}$ (diffusing tip). To avoid significant tissue hyperthermia the power density at the fibre tip was set at $100 \mathrm{~mW}$ for the flat tip and $400 \mathrm{~mW} \mathrm{~cm}^{-1}$ for the diffusing tip. For each application treatment ranged from five to eight minutes, and to irradiate all the malignant tissue there were three (at $2 \mathrm{pm}, 6 \mathrm{pm}$, and $10 \mathrm{pm}$ ) or four (at $3 \mathrm{pm}, 6 \mathrm{pm}$, $9 \mathrm{pm}$, and 12 midnight) applications per treatment session. Patients were treated at intervals ranging between three and six months, and the results of treatment assessed endoscopically with biopsy at four to six weeks and then every eight to 12 weeks.

\section{Results}

Between one and five PDT treatments were given over periods of six to 24 months (Table II). The median hospital stay was four days (range 4-10). Treatment was tolerated well by all patients. Three patients developed moderate skin photosensitivity reactions with erythema and oedema after inadvertent sun exposure. There were no local complications of treatment, in particular no clinical pancreatitis or perforations.

Group $I$ - there were four patients, and in all there was no macroscopic tumour at four to six weeks after treatment (Table II). Three patients went into remission with negative biopsies, and their biliary stents were either removed or 'disappeared' - that is, passed spontaneously. Tumour recurred in all three, however, after periods ranging from eight to 12 months, and in two patients there was also spread to adjacent duodenum. These three patients have received further PDT treatment. The fourth patient had residual tumour in the submucosa on biopsy, and there was macroscopic recurrence at six months.

Group $I I$ - there were three patients, and in each there was an appreciable response with reduced tumour bulk, but macroscopic tumour remained after PDT (Table II). 

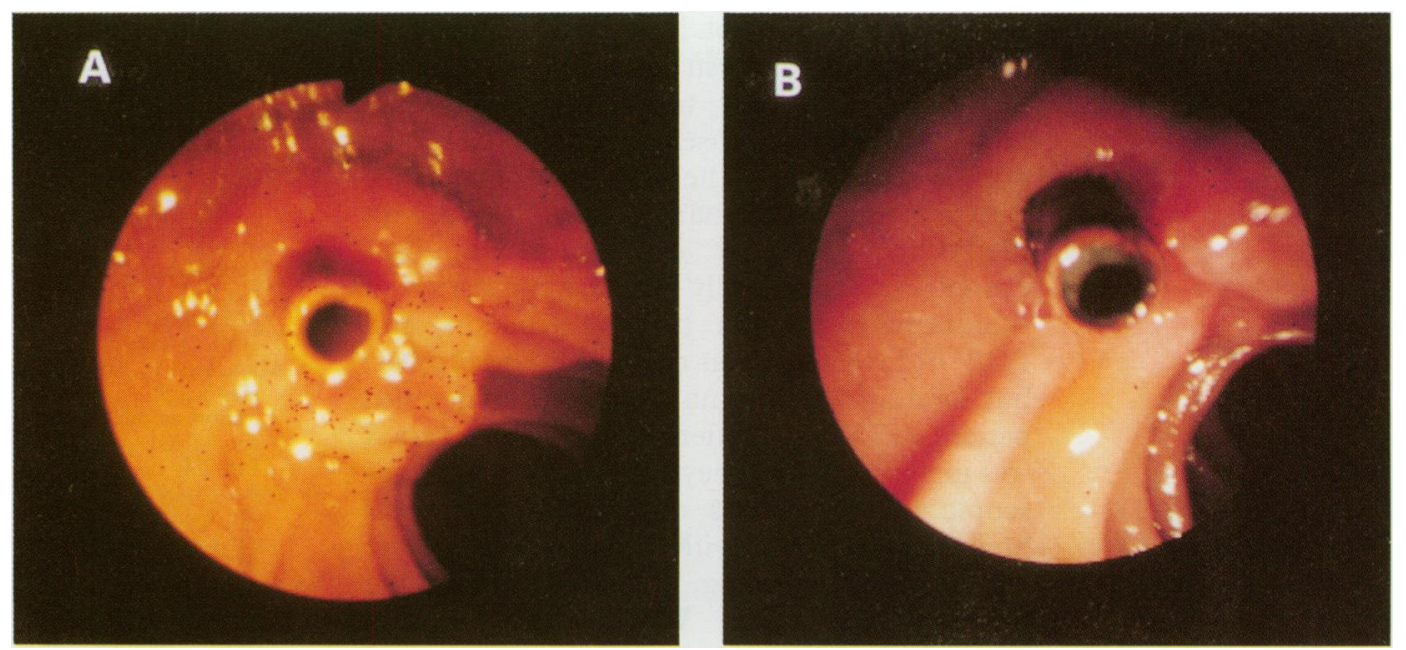

Figure 2: Patient 6-partial response. (B) Before treatment; (B) after treatment.

Group III - there were three patients (Table II). One patient with hepatic metastases had considerable endoscopic improvement, but died four months later from disseminated disease. In two patients with extensive disease there was no significant improvement and they were referred for by pass surgery.

\section{Discussion}

The patients recruited for the study would otherwise had only palliative treatment with endoscopic drainage or biliary bypass surgery. Although jaundice is relieved and consequently quality of life improved, there is no definitive treatment even though at presentation ampullary carcinomas are usually small and without spread. There is therefore scope for exploring new treatments less invasive than pancreaticoduodenectomy. An ideal treatment should be safe, non-toxic, and selective - that is, eradicate tumour with minimal damage to surrounding normal tissue. PDT, a treatment first described over a century ago, ${ }^{20}$ may fulfil these criteria. In a large number of studies the treatment has been shown to be safe and nontoxic and the only side effect is skin photosensitivity caused by retention of the photosensitiser for up to eight weeks. Selectivity is due to preferential uptake of the photosensitiser by tumour compared with normal tissues $^{14}$ together with accurate targeting of the activating laser light. ${ }^{13}$

This is the first series of patients with periampullary carcinoma treated by PDT. The results show that PDT is effective and in most cases there was considerable tumour destruction. The results in group I patients were particularly encouraging with no residual macroscopic tumour in all four cases, and in three, no residual microscopic tumour. In addition, as in experimental colon cancer, healing after PDT was by regeneration of normal mucosa rather than scarring. ${ }^{15}$ Three patients had periods of remission ranging from eight to 12 months during which there was normal biliary drainage without the need for endoprostheses. They then relapsed, however, presumably because of residual foci of tumour deep to the regenerated normal epithelium. It should be possible to improve treatment and perhaps prevent relapse in two ways. Firstly, to attempt to eradicate the tumour by carrying out repeat PDT even when evidence of macroscopic or microscopic disease is lacking, for example at intervals of three to six months. And secondly, more accurate assessment of tumour size before treatment and early detection of residual or recurrent tumour after treatment by endoscopic ultrasound - the most accurate method for staging local spread. ${ }^{21}$ In addition, new second generation photosensitisers are being introduced that have higher selectivity and shorter periods of skin photosensitivity. ${ }^{22}$ The treatment is also safe with skin photosensitivity as the only complication. In experimental animals there is a risk of duodenal perforation with PDT to the periampullary region, ${ }^{23}$ but in our study there was no evidence of significant damage to adjacent normal tissues.

Because of the limited penetration of light in tissues, more than one light application per treatment was required to ensure activation of the photosensitiser throughout the tumour, and in the early part of the study when a flat tipped fibre was used, early repeat PDT was required to obtain a response in patients with large tumours. The use of fibres with diffusing tips in the later part of the study therefore proved a significant advance because a larger tumour volume could be treated per light application avoiding the need for more than one treatment session to eradicate tumour.

There are alternatives for patients with ampullary carcinoma not suitable for pancreaticoduodenectomy. The simplest is palliative biliary drainage by endoscopy ${ }^{512}$ or surgery (usually combined with duodenal bypass), ${ }^{4-9}$ since ampullary carcinoma may progress only slowly and often the patients are elderly and frail, but the opportunity to cure small tumours is lost. Local surgical resection has been associated with an unacceptably high recurrence rate $^{9}$ and also is invasive with associated morbidity and mortality.

Other endoscopic treatments include snare resection and Nd:YAG laser photodestruction. Snare resection will reduce tumour bulk but may be complicated by severe haemorrhage ${ }^{12}$ 
and will probably not have the potential for cure. For tumour destruction Nd:YAG laser may be comparable to PDT without the problem of skin photosensitivity although may not be as safe and healing may take place with scarring rather than regeneration as with PDT. ${ }^{16}$ Ponchon et al treated ampullary tumours endoscopically with a combination of snare resection, laser photodestruction, and PDT. ${ }^{12}$ Treatment was curative for adenomas, but for adenocarcinoma (Nd:YAG laser seven patients, PDT one patient) tumour destruction was incomplete and they considered that endoscopic treatment was only palliative. ${ }^{12}$ Our preliminary results with PDT, however, are far more encouraging, perhaps offering the potential for cure. When the optimum schedule for PDT of ampullary carcinoma has been determined, we plan a randomised controlled trial of PDT versus Nd:YAG laser treatment for periampullary carcinoma. In addition, McCaughan et al have repeatedly treated a patient with a cholangiocarcinoma with seven courses of PDT resulting in a four year survival period, suggesting that PDT may also be of benefit for malignancy higher in the biliary tree. ${ }^{24}$ That PDT can be repeated may be an important advantage over brachytherapy for intraluminal treatment of cholangiocarcinoma.

In conclusion, PDT causes safe and effective tumour destruction in patients with ampullary carcinoma with periods of clinical remission for tumours confined to the papilla. Advances and refinements of technique may lead to improved treatment and possible cure for patients with small tumours.

The Department of Surgery is supported by the Cancer Research Campaign and AMA was in receipt of a CRC Training Fellowship. The authors wish to thank Sisters E Bewick, A Rowntree-Taylor, S Willmer, and their staffs for the invaluable help they provided during the study.

1 Barton RM, Copeland EM. Carcinoma of the ampulla of Vater. Surg Gynecol Obstet 1983; 156: 297-301.

2 Delcore M, Connor CS, Thomas JH, Friesen SR, Hermreck AS. Significance of tumour spread in adenocarcinoma of AS. Significance of tumour spread in adenocarcinoma

3 Whipple AO, Parsons WB, Mullins CR. Treatment of carcinoma of the ampulla of Vater. Ann Surg 1935; 102: 763-79.
4 Jones BA, Langer B, Girotti M. Periampullary tumours: which ones should be resected? Am $\mathcal{f}$ Surg 1985; 149: 46-51.

5 Grace PA, Pitt HA, Tomkins RK, DenBester L, Longmire WP. Decreased morbidity and mortality after pancreaticoduodenectomy Am $\mathcal{F}$ Surg 1986; 151: 141-9.

6 Tarazi RY, Hermann RE, Vogt DP, Hoerr SO, Esselstyn CB Jr, Cooperman AM, et al. Results of surgical treatment of periampullary tumours: a thirty-five year experience. of periampullary tumours:
Surgery 1986; 100: 716-23.

7 Neoptolemos JP, Talbot IC, Carr-Locke DL, Shaw DE, Cockleburgh R, Hall AW, et al. Treatment and outcome in 52 consecutive cases of ampullary carcinoma. Br $\mathcal{f}$ Surg 1987; 74: 957-61

8 Michelassi F, Erroi F, Dawson PJ, Pietrabissa A, Noda S, Handcock M, et al. Experience with 647 consecutive tumors of the duodenum, ampulla, head of the pancreas, and distal common bile duct. Ann Surg 1989; 210: 544-54.

9 Monson JRT, Donohue JH, McEntee GP, Mcllrath DC, van Heerden JA, Shorter RG, et al. Radical resection for carcinoma of the ampulla of Vater. Arch Surg 1990; 126: 353-7.

10 Goldberg M, Zamir O, Hadary A. Wide local excision as an alternative treatment for periampullary carcinoma. an alternative treatment for periamp

11 Farouk M, Niotis M, Branum GD, Cotton PB, Meyers WC. Indications for and the technique of local resection of tumors of the papilla of Vater. Arch Surg 1991; 126: 650-2.

12 Ponchon T, Berger F, Chavaillon A, Bory R, Lambert R. Contribution of endoscopy to diagnosis and treatment of tumors of the ampulla of Vater. Cancer 1989; 64: 161-7.

13 Anonymous. Photodynamic therapy. Lancet 1989; ii: $81-2$.

14 Gregorie HB, Horger EO, Ward JL, Green JF, Richards T, Robertson HC, et al. Haematoporphyrin-derived fluorescence in malignant neoplasms. Ann Surg 1968; 167: 820-8.

15 Dougherty TJ. Photoradiation therapy (PRT) of malignant tumours. CRC Crit Rev 1984; 2: 83-116.

16 Barr H, Tralau CJ, Boulos PB, MacRobert AJ, Tilly R, Bown SG. The contrasting mechanisms of colonic damage between photodynamic therapy and thermal injury. Photochem Photobiol 1987; 46: 795-800.

17 Lipson RL, Baldes EJ, Olsen AM. The use of a derivative of haematoporphyrin in tumour detection. $\mathcal{f}$ Natl Cancer Inst 1961; 26: 1-11.

18 Gomer CJ, Dougherty TJ. Determination of ${ }^{3} \mathrm{H}$ and ${ }^{14} \mathrm{C}$ $\mathrm{HpD}$ distribution in malignant and normal tissue. Cancer Res 1979; 39: 146-51.

19 Kessel D, Cheng M. Biological and biophysical properties of the tumor-localising component of haematoporphyrin derivative. Cancer Res 1985; 45: 3053-7.

20 Von Tappeiner H, Jesionek A. Theraputischen Versuche mit fluorescierenden Stoffen. Munchener Medizinische Wochenschrift 1903; 47: 2042-4.

21 Rosch T, Braig C, Gain T, Feuerbach S, Rudiger Siewert J, et al. Staging of pancreatic and ampullary carcinoma by endoscopic ultrasonography. Gastroenterology 1992; 102: 188-99.

22 Ris HB, Altermat HJ, Inderbitzi R, Hess R, Nachbur B, Stewart JCM, et al. Photodynamic therapy with chlorins for diffuse malignant mesothelioma: initial clinical results. Br f Cancer 1991; 64: 1116-20.

23 Nuutinen PJO, Chatlani PT, Bedwell J, MacRobert AJ, Philips D, Bown SG. Distribution and photodynamic effect of disulphonated aluminium phthalocyanine in the pancreas and adjacent tissues in the Syrian golden pancreas and adjacent tissues in the

24 McCaughan JS, Mertens BF, Cho C, Barabash RD, Payton HW. Photodynamic therapy to treat tumors of the extrahepatic bile ducts. Arch Surg 1991; 126: 111-3. 